\title{
Dynamic Probit Models and Financial Variables in Recession Forecasting
}

\author{
Henri Nyberg \\ University of Helsinki and HECER
}

Discussion Paper No. 225

June 2008

ISSN 1795-0562

HECER - Helsinki Center of Economic Research, P.O. Box 17 (Arkadiankatu 7), FI-00014 University of Helsinki, FINLAND, Tel +358-9-191-28780, Fax +358-9-191-28781, E-mail info-hecer@helsinki.fi, Internet www.hecer.fi 


\title{
Dynamic Probit Models and Financial Variables in Recession Forecasting*
}

\begin{abstract}
In this paper various financial variables are examined as predictors in new dynamic probit models to predict the probability of a recession in the United States and Germany. Following the findings of previous studies, the domestic term spread proved to be an important predictive variable, but several lagged values of stock returns and the foreign term spread are also statistically significant predictive variables for both countries. The interest rate differential between the U.S. and Germany is also a useful predictor in the case of Germany. Examined dynamic probit models outperform the traditional static model giving accurate out-of-sample forecasts for the latest recession period that began in both countries in 2001.
\end{abstract}

JEL Classification: C22, C25, E32, E37

Keywords: Dynamic probit models, recession forecast, term spread, stock return

Henri Nyberg

Department of Economics

University of Helsinki

P.O. Box 17 (Arkadiankatu 7)

FI-00014 University of Helsinki

FINLAND

e-mail: henri.nyberg@helsinki.fi

* The author would like to thank Heikki Kauppi, Markku Lanne and Pentti Saikkonen for constructive comments. The author is responsible for remaining errors. Financial support from the Research Foundation of the University of Helsinki, Academy of Finland, the Okobank Group Research Foundation and the Finnish Foundation for Advancement of Securities Markets is gratefully acknowledged. 


\section{Introduction}

A substantial amount of research has considered the predictive ability of various financial variables to predict the economic growth and recession periods in different countries. Much of the previous analysis is focused on time series models, where the dependent variable is "continuous" such as the growth rate of GDP and industrial production. In the econometric literature, however, forecasting the values of the binary recession indicator with probit or logit models has attracted attention in recent years when some new time series models for binary dependent variables have been suggested. For instance, Rydberg and Shephard (2003), Chauvet and Potter (2005) and Dueker (2005) proposed new dynamic extensions to the traditional static model where the response probability is only a function of the explanatory variables.

Particularly, the term spread which is the difference between the long- and shortterm interest rate, is suggested in the literature to be a useful predictor of future economic growth and recession periods (e.g. Estrella and Mishkin, 1998 and Estrella, 2005a). However, other financial variables have also been postulated. If the domestic spreads are useful predictors, then the foreign spreads as well may have predictive content in the domestic country (Bernard and Gerlach, 1998). An alternative predictive variable is the interest rate differential between the U.S. and Germany. To the best of our knowledge, there are no previous empirical studies concerning this variable in recession forecasting. The theoretical arguments for the possible predictive power are not obvious either. Further, as a forward-looking variable, the stock market return should also have additional predictive power with interest rate based predictive variables.

In this paper, the main interest is to apply the dynamic models suggested by Kauppi and Saikkonen (2007) to predict monthly recession periods in the United States and Germany. Kauppi and Saikkonen (2007) have proposed a new iterative forecasting approach to multiperiod forecasts in binary time series, and developed new model variants where the autoregressive structure of the model is employed in the model equation with other explanatory variables.

This paper's findings extend the earlier evidence in many different ways. First of all, we can confirm that the domestic term spreads are the primary predictive 
variables, but stock market returns also have statistically significant predictive power in both countries. In the case of German recessions, the interest rate differential and the foreign German term spread for the U.S. recessions are also useful predictors. The foreign U.S. term spread is also a statistically significant predictor in all insample models for German recession periods but its out-of-sample predictive content seems to be poor. We also found some evidence that the term spread appears to have an asymmetric influence on the recession probability depending on the state of the economy. Overall, dynamic probit models outperform the traditional static recession prediction models in terms of in-sample and out-of-sample predictions. In out-ofsample forecasting, the best models provide accurate forecasts in terms of predictive ability and recession signals for the state of the economy in the considered out-ofsample period, which began in 1995.

The paper is organized as follows. Section 2 presents the probit models that will be used in forecasting. The issues in multiperiod forecasts of the recession indicator are illustrated in Section 3. In Section 4 the in-sample and out-of-sample predictions of recession periods in the U.S. and Germany are provided. Finally, conclusions are presented in Section 5.

\section{Dynamic Probit Models}

In binary time series analysis, the dependent variable $y_{t}, t=1,2, \ldots, T$, is a time series of the realization of the corresponding stochastic process that only takes on values one and zero. In recession forecasting, the value of an observable binary recession indicator depends on the state of the economy in the following way

$$
y_{t}=\left\{\begin{array}{l}
1, \text { if the economy is in a recessionary state at time } t \\
0, \text { if the economy is in an expansionary state at time } t
\end{array}\right.
$$

Conditional on the information set $\Omega_{t-1}, y_{t}$ has a conditional Bernoulli distribution

$$
y_{t} \mid \Omega_{t-1} \sim B\left(p_{t}\right)
$$

In the Bernoulli distribution, if $E_{t-1}(\cdot)$ and $P_{t-1}(\cdot)$ signify the conditional expectation and conditional probability given the information set $\Omega_{t-1}, p_{t}$ is the conditional 
probability that $y_{t}$ takes the value 1

$$
E_{t-1}\left(y_{t}\right)=P_{t-1}\left(y_{t}=1\right)=\Phi\left(\pi_{t}\right)=p_{t}
$$

In the case of probit models, the link function between the model equation $\pi_{t}$ and the conditional probability $p_{t}$ is a standard normal distribution function $\Phi(\cdot)$, where $\pi_{t}$ is a linear function of variables included in the information set $\Omega_{t-1}$.

In previous recession forecasting research, the "static" model

$$
\pi_{t}=\omega+\boldsymbol{x}_{t-k}^{\prime} \boldsymbol{\beta}
$$

has been the most commonly used binary time series model. All explanatory variables are included in vector $\boldsymbol{x}_{t-k}$, where $k$ indicates the employed lag orders of explanatory variables. In recession forecasting, Estrella and Hardouvelis (1991), Estrella and Mishkin (1998), and Bernard and Gerlach (1998), among others, have used the static model (4).

The modeling and forecasting of macroeconomic variables in traditional autoregressive time series models have clearly demonstrated the importance of using the lagged values of the dependent variable in the predictive model. One main shortcoming of the static model (4) is that it can be misspecified because it does not take the autocorrelation structure of the binary time series into account (Dueker, 1997). In recession forecasting, this means that the lagged state of the economy should also be included in the model. Thus, a natural dynamic extension to the static model (4) is to include the lagged value of the time series $y_{t}$ in the model equation

$$
\pi_{t}=\omega+\delta_{1} y_{t-1}+\boldsymbol{x}_{t-k}^{\prime} \boldsymbol{\beta}
$$

This "dynamic" probit model ${ }^{1}$ is used in the recession forecasting studies of Dueker (1997), Valckx et al. (2002) and Moneta (2003).

Kauppi and Saikkonen (2007) extend the dynamic model (5) by adding a lagged value of the $\pi_{t}$ to the model equation. This model is

$$
\pi_{t}=\omega+\alpha_{1} \pi_{t-1}+\delta_{1} y_{t-1}+\boldsymbol{x}_{t-k}^{\prime} \boldsymbol{\beta},
$$

\footnotetext{
${ }^{1}$ All extensions for the static model (4) are called dynamic models, but in particular model (5) is called the "dynamic" probit model.
} 
and is referred to the "dynamic autoregressive" model. ${ }^{2}$ It is also possible to study an "autoregressive" model, where the coefficient $\delta_{1}$ for the lagged $y_{t-1}$ is zero

$$
\pi_{t}=\omega+\alpha_{1} \pi_{t-1}+\boldsymbol{x}_{t-k}^{\prime} \boldsymbol{\beta}
$$

By recursive substitution, it can be shown that the dynamic autoregressive model (6) is an "infinite" order extension of the dynamic model (5)

$$
\pi_{t}=\sum_{i=1}^{\infty} \alpha_{1}^{i-1} \omega+\delta_{1} \sum_{i=1}^{\infty} \alpha_{1}^{i-1} y_{t-i}+\sum_{i=1}^{\infty} \alpha_{1}^{i-1} \boldsymbol{x}_{t-k-i}^{\prime} \boldsymbol{\beta} .
$$

This presentation shows that if, for example, the longer history of the explanatory variables is useful in forecasting, autoregressive model specifications, (6) and (7) could be useful parsimonious models. Rydberg and Shephard (2003) proposed a somewhat similar model as (6), but in their model the infinite history of the explanatory variables is not employed. Throughout this paper, it is assumed that there are only one lagged value of the model equation $\pi_{t}$ and dependent recession indicator $y_{t}$ but, of course, it is possible to include several lags in the model equation.

One interesting extension to model (7) is to include an interaction term in the model equation

$$
\pi_{t}=\omega+\alpha_{1} \pi_{t-1}+\boldsymbol{x}_{t-k}^{\prime} \boldsymbol{\beta}+y_{t-a} \boldsymbol{x}_{t-k} \boldsymbol{\gamma}
$$

where the lag $a, a \geq 1$, should be chosen. In this model, the impact of the explanatory variables depend on the state of the economy (cf. Kauppi and Saikkonen, 2007). Of course, it is also possible to use the lagged value $y_{t-1}$ in the model equation (8).

Parameter estimation of models (4)-(8) can be carried out by maximum likelihood (ML) methods. The maximum likelihood estimate $\hat{\boldsymbol{\theta}}$ for the vector of parameters $\boldsymbol{\theta}$ is found by maximizing the full sample log-likelihood function

$$
l(\boldsymbol{\theta})=\sum_{t=1}^{T} l_{t}(\boldsymbol{\theta})=\sum_{t=1}^{T}\left(y_{t} \log \left(\Phi\left(\pi_{t}\right)\right)+\left(1-y_{t}\right) \log \left(1-\Phi\left(\pi_{t}\right)\right)\right) .
$$

At the present time there is no formal proof of the asymptotic distribution of the maximum likelihood estimate $\hat{\boldsymbol{\theta}}$ in the models with autoregressive structure (6)(8). ${ }^{3}$ However, it seems reasonable to assume that with regularity conditions, such

\footnotetext{
${ }^{2}$ In this paper the same model names suggested by Kauppi and Saikkonen (2007) are used.

3 de Jong and Woutersen (2007) have shown that under appropriate regularity conditions the conventional large sample theory and asymptotic distribution (10) holds for the dynamic model (5).
} 
as the stationarity of explanatory variables and the correctness of the probit model specification, the asymptotic distribution is

$$
T^{1 / 2}\left(\hat{\boldsymbol{\theta}}-\boldsymbol{\theta}_{0}\right) \stackrel{L}{\longrightarrow} N\left(\mathbf{0}, \mathcal{I}\left(\boldsymbol{\theta}_{0}\right)^{-1}\right),
$$

where the asymptotic covariance matrix is the inverse of information matrix $\mathcal{I}\left(\boldsymbol{\theta}_{0}\right)$ evaluated at the point of the true parameter value $\boldsymbol{\theta}_{0}$. Nevertheless, the use of overlapping forecast horizon in the multiperiod forecasting or an incorrect model specification indicates that the standard errors based on the asymptotic distribution (10) become inconsistent (Estrella and Rodrigues, 1998). The asymptotic distribution of the maximum likelihood estimate in the case of a misspecified model is

$$
T^{1 / 2}\left(\hat{\boldsymbol{\theta}}-\boldsymbol{\theta}_{*}\right) \stackrel{L}{\longrightarrow} N\left(\mathbf{0}, \mathcal{I}\left(\boldsymbol{\theta}_{*}\right)^{-1} \mathcal{J}\left(\boldsymbol{\theta}_{*}\right) \mathcal{I}\left(\boldsymbol{\theta}_{*}\right)^{-1}\right),
$$

where $\boldsymbol{\theta}_{*}$ is not necessarily the true parameter value $\boldsymbol{\theta}_{0}$. Kauppi and Saikkonen (2007) propose consistent robust standard errors, which are obtained from the diagonal elements of the sample analogue of the asymptotic covariance matrix from (11). As in the correctly specified model, the matrix $\mathcal{I}\left(\boldsymbol{\theta}_{0}\right)$ can be consistently estimated by its sample analogue

$$
\boldsymbol{I}_{T}(\hat{\boldsymbol{\theta}})=-\frac{1}{T} \sum_{t=1}^{T}\left(\frac{\partial^{2} l_{t}(\hat{\boldsymbol{\theta}})}{\partial \boldsymbol{\theta} \partial \boldsymbol{\theta}^{\prime}}\right) .
$$

If the model is correctly specified, then $\mathcal{I}\left(\boldsymbol{\theta}_{0}\right)=\mathcal{J}\left(\boldsymbol{\theta}_{0}\right)$, where the matrix $\mathcal{J}\left(\boldsymbol{\theta}_{0}\right)$ can be estimated with an outer product of the gradient estimator. In the misspecified model, Kauppi and Saikkonen (2007) suggest a general consistent estimator for $\mathcal{J}\left(\boldsymbol{\theta}_{*}\right)$ which is based on the Parzen kernel.

\section{Multiperiod Forecasts for the Recession Indicator}

As Kauppi and Saikkonen (2007) show, the one period forecast and multiperiod forecasts in models (4)-(8) can be constructed by explicit formulae. In practice, in recession forecasting the fact that the realized values of the recession indicator (1) are known after a considerable delay should be taken into account. The initial announcements of many of the major indicators of economic activity are preliminary and in many times subject to substantial revisions. Thus it is not possible to identify the 
month of a peak or trough in real time. For instance, the most recent decisions of business cycle peak and trough months defined by the $\mathrm{NBER}^{4}$ show that it has taken at least five up to twenty months before the business cycle turning point was identified.

In this study, this "publication lag" in the recession indicator is assumed to be nine months. This means that, for example, the NBER has, at least some preliminary, information about the latest values of important macroeconomic variables which are crucial to determining the value of the recession indicator. Due to this assumed delay, the forecast horizon $h$ consists of two periods. The first nine months $h=1,2, \ldots, 9$, are related to predictions of the most recent values and the current value of the recession indicator. The longer forecasts, $h \geq 10$, are perhaps the most significant because at these horizons the future values of the recession indicator are of interest. The values of the explanatory variables are also unknown during these months. Later in this paper this "ahead" forecast horizon is denoted by $h^{f} .5$

By the law of iterated expectations, optimal in the mean square sense $h$ period forecast for $y_{t}$, based on information set $\Omega_{t-h}{ }^{6}$, is the conditional expectation

$$
E_{t-h}\left(y_{t}\right)=E_{t-h}\left(P_{t-1}\left(y_{t}=1\right)\right)=E_{t-h}\left(\Phi\left(\pi_{t}\right)\right) .
$$

Multiperiod forecasts can be made by two methods (cf. forecasts in linear autoregressive models, for example Marcellino, Stock, and Watson, 2006). Using the most general dynamic autoregressive probit model (6) as an example, the "direct" forecast for the conditional probability in (12), at time $t-h$, is given by

$$
P_{t-1}\left(y_{t}=1\right)=\Phi\left(c+\alpha_{1} \pi_{t-1}+\delta_{1} y_{t-l}+\boldsymbol{x}_{t-k} \boldsymbol{\beta}\right)
$$

where the conditions $l \geq h$ and $k \geq h^{f}$, but at least $k \geq 1$, must hold. This forecast is "direct" in the sense that the right hand side gives the $h$ step forecast "directly".

An "iterative" forecasting approach is computationally more difficult than the direct method. The forecasts made at time $t-h$ require evaluating the conditional

\footnotetext{
${ }^{4}$ http://www.nber.org/cycles/cyclesmain.html.

${ }^{5}$ When the forecasting horizon is $h \geq 10$, then $h^{f}$ is defined as $h^{f}=h-9$, where the number 9 is the assumed publication lag in $y_{t}$.

${ }^{6}$ If $h \leq 9$, then the information set is $\Omega_{t-h}=\left\{y_{t-h}, y_{t-h-1}, \ldots, \boldsymbol{x}_{t-1}, \boldsymbol{x}_{t-2}, \ldots\right\}$. On the other hand, when $h \geq 10$ which means that we are interested the future values of the recession indicator, the information set is $\Omega_{t-h}=\left\{y_{t-h}, y_{t-h-1}, \ldots, \boldsymbol{x}_{t-h^{f}}, \boldsymbol{x}_{t-h^{f}-1}, \ldots\right\}$, where $h^{f}$ is defined as above.
} 
expectation

$$
E_{t-h}\left(y_{t}=1\right)=E_{t-h}\left(P_{t-1}\left(y_{t}=1\right)\right) .
$$

In the case of the dynamic autoregressive model (6), the model is

$$
P_{t-1}\left(y_{t}=1\right)=\Phi\left(c+\alpha_{1} \pi_{t-1}+\delta_{1} y_{t-1}+\boldsymbol{x}_{t-k} \boldsymbol{\beta}\right) .
$$

As seen in equation (15), there is an unknown value of $y_{t-1}$ in the model equation. Explanatory variables $\boldsymbol{x}_{t-k}$ should be tailored in the same way as in the direct forecasting in equation (13) assuming that the same conditions for $k$ hold true. The binary nature of dependent variable $y_{t}$ allows one to explicitly compute the multiperiod iterative forecasts accounting for all possible paths and their probabilities through to $y_{t-h}$ until $y_{t}$. Further, the iterative multiperiod forecast is computed using iteratively the same one-period model equation (15). Therefore, before evaluating the out-of-sample forecasting performance of different models, various in-sample forecasting models can be estimated using the model equations (13) and (15).

\section{Empirical Analysis of Recession Periods in the United States and Germany}

\subsection{Data and Previous Findings in Recession Forecasting}

The data set includes the values of the dependent recession indicator $y_{t}$ and considered explanatory variables $\boldsymbol{x}_{t}$ in the U.S. and Germany covering the period from January 1971 to December 2007. Because of the assumed nine-month publication lag in the dependent recession indicator $y_{t}$, the recession periods are known up to March 2007 although the explanatory variables are known up to December 2007. The data set is collected from various of sources which are documented in Appendix.

In the literature, much of the previous analysis of economic activity is based on the "continuous" variables, such as industrial production growth or GDP growth, where the dependent variable can take, in principle, any real number. ${ }^{7}$ Estrella and

\footnotetext{
${ }^{7}$ For more detailed evidence in these models, see the comprehensive surveys of Stock and Watson (2003) and Estrella (2005a) with references to other studies.
} 
Hardouvelis (1991) propose using a binary recession indicator (1) and the probit model to predict the probability of recession. After that, the studies of Dueker (1997, 2002), Bernard and Gerlach (1998), Estrella and Mishkin (1998), Boulier and Steckler (2000), Valckx et al. (2001), Moneta (2003), Estrella, Rodrigues and Schich (2003) and Wright (2006), among others, consider recession prediction with various financial variables. In this paper, we examine domestic and foreign term spreads, stock market returns and the interest rate differential between the United States and Germany as predictive variables and they are discussed in detail below.

The term spread

$$
S P_{t}=R_{t}-i_{t}
$$

which is defined as the difference between the long-term interest rate $R_{t}$ and the short-term interest rate $i_{t}$, has been the most commonly used predictor in recession forecasting. Estrella and Hardouvelis (1991) is among the first studies to find that the term spread is a useful predictor of economic growth and recession periods in the U.S. Bernard and Gerlach (1998) and Moneta (2003) present the same kind of evidence for Germany. Estrella (2005a, 2005b) provides an extensive literature review and the main theoretical basis for the predictive power of the term spread. The most widely used simplified argument rests on the fact that by the expectation hypothesis of interest rates, the long-term interest rate reflects the expectations of the coming values of the short-term interest rate. Thus the value of the term spread reflects expectations about future monetary policy. As Estrella (2005a), for example, argues, a tightening monetary policy usually slows down the economic activity and flattens the term spread.

An important issue in recession forecasting is the stability of relationships between explanatory variables and recession periods. In the case of term spread, Estrella et.al. (2003) and Wright (2006) in the static model (4) and recently Kauppi (2008) in the dynamic model (5) find no evidence of structural breaks between the term spread and recession periods in the U.S. Estrella et.al. (2003) propose that the recession prediction models are even more stable than the forecasting models for the economic growth.

In the static probit model (4), Bernard and Gerlach (1998) show that the foreign 
term spreads are also useful additional predictive variables albeit secondary compared with the domestic term spread. Correlations between economic activity and regularities in business cycles across countries with reflections of foreign monetary policy concerning the domestic economy are possible explanations for this potential predictive power.

Foreign term spreads have previously not been examined as predictors in dynamic probit models. The same is true for the interaction model (8) where the term spread could have an asymmetric impact on the recession probability. There is evidence that monetary policy has asymmetric effects on the real economy depending on the economy's state (e.g. Morgan, 1993 and Florio, 2004). This means that the term spread could have a different impact on the recession probability in recessionary compared to expansionary business cycle phases.

As a forward-looking variable dependent on the expectations of future dividends and profitability of firms, lagged stock returns $r_{t}$ should have additional predictive power along with term spreads in recession predictions. Some evidence of predictive content can be found, for example, in the studies of Estrella and Mishkin (1998) and Valckx et al. (2001). In the former, the stock return is the only variable that has outof-sample predictive power with the domestic term spread to predict recession periods in the U.S. As Fama (1990) pointed out with models for continuous variables, one interesting way to extend the predictive model is to experiment with several lagged stock returns as predictors, because the predictive power of past returns concerning economic activity appears to decay slowly. Therefore, a single stock return lag could be too noisy a recession predictor at the monthly frequency.

With term spreads and stock returns, the interest rate differential

$$
I S_{t}=i_{t}^{U S}-i_{t}^{G E}
$$

which is defined as the difference between the short-term interest rates in the U.S. $\left(i_{t}^{U S}\right)$ and Germany $\left(i_{t}^{G E}\right)$, may also have some explanatory power. To the best of our knowledge, there is no earlier evidence of its usefulness in recession prediction. Davis and Fagan (1997) consider it in predictive models for the output growth in EU countries, and the evidence is quite weak. 
It is not evident what is the theoretical transition mechanism behind the connection between interest rate differentials and recessions. It can be, however, argued that under flexible exchange rates, perfect capital mobility and uncovered interest rate parity, the difference between domestic and foreign interest rates is equal to the expected change in the exchange rate (e.g. Romer 2001, 231). On the other hand, if the domestic interest rate is higher than the foreign rate, for example because of higher economic activity in the domestic country, domestic assets tend to become more attractive, other things being equal. To maintain a capital market equilibrium, the exchange rate will first appreciate. The appreciation of the domestic currency and, for instance, higher inflation due to higher economic growth will lead to a considerable deterioration in the competitiveness and the profitability of the domestic firms. Thus, in the future, it is expected that the domestic economic activity will also slow down as before in the domestic country and the interest rate differential will probably narrow as a result of monetary policy easing in the domestic country.

Table 1 presents the descriptive sample statistics of the whole sample period. Figures 1 and 2 show the time series of variables and the recession periods. The values of the term spreads are on average positive, but in the vicinity of recession periods the term spreads are close to zero or even negative. The interest rate differential $I S$ seems to be mostly negative in connection to recession periods in Germany, which means that the short-term interest rate is higher in Germany at those periods. The correlation between interest rate differential and German term spread is higher than in the case of the U.S. Further, the correlation between the U.S. and German term spreads is a moderate 0.33. As seen in Figure 2, the stock returns are highly volatile and in both countries the returns tend to be negative some months before the recession begins, and respectively, returns tend to be positive some months before it ends.

\subsection{In-Sample Results and Model Selection}

In the in-sample analysis, the sample period from January 1972 to December 1994 is used to examine the performance of different probit models with various combinations of explanatory variables. In the model evaluation, the main goodness-of-fit measure is the pseudo- $R^{2}$ measure suggested by Estrella (1998). According to the in-sample 
performance of different models, the optimal lag orders for the explanatory variables $\boldsymbol{x}_{t-k}$ and the lagged value of the dependent variable $y_{t-l}$, where $k$ and $l$ are allowed to change between one to 12, are experimented with. Among others, Estrella and Mishkin (1998) and Kauppi and Saikkonen (2007) have emphasized the importance of these selections. In practise, it has been common to select the lag orders equal to forecast horizon $k=l=h$ although the latest values of predictive variables are not necessarily the best ones in terms of predictive power.

Tables 3 and 4 show estimation results for the estimated parameter coefficients in the best in-sample models. ${ }^{8}$ In parentheses are the robust standard errors, which are based on the asymptotic distribution (11). The main findings are very much same in both countries. The overall model selection evidence reflects that the first lag of the dependent variable $y_{t-1}$ is superior compared with the alternatives in both countries and is a strongly statistically significant predictor. With longer lags $l>1$, the statistical improvement in predictive accuracy appears to diminish. This indicates that the iterative forecasts, presented in Section 3, could be superior to horizonspecific direct forecast in out-of-sample forecasting. This is in line with the findings of Kauppi and Saikkonen (2007).

In the case of explanatory variables, the sixth lags for the domestic and foreign term spreads performed consistently better, on average, than the alternative selections in different probit models in both countries. The best lag orders for stock return lags and for the interest rate differential are shown in the first column of Table 3 and Table 4. Taking a closer look at the estimation results, the domestic term spread is the primary predictive variable, but the foreign term spread and most of stock return lags are also statistically significant predictors. The signs of regression coefficients are negative as expected. This means that the probability of recession is higher when the values of the term spreads are relatively low. Negative stock returns also increase the probability of recession.

The interest rate differential $\left(I S_{t}\right)$ is statistically significant predictive variable in the case of Germany (Table 4). A negative coefficient means that the recession probability increases when the German short-term interest rate is higher than the

\footnotetext{
${ }^{8}$ Details on all model selection results are available upon request.
} 
U.S. one. Although the predictive content in Germany, the interest rate differential is not a statistically significant predictor of the U.S. recession periods and, therefore, it is withdrawn from the predictive models of the U.S. recessions.

Overall, based on the in-sample evidence in both countries, it is clear that the foreign term spreads, several lagged stock returns and the interest rate differential in Germany add significant predictive power to forecast the recession periods compared to only the domestic term spread. The dynamic models outperform the static model (4) in terms of in-sample predictions. However, also the static model with all examined explanatory variables outperforms the traditional static model where the domestic term spread is the only predictor in both countries (the first and the second models in Tables 3 and 4).

When comparing different dynamic models, the dynamic model (5) produces the best in-sample predictions in the United States presented in Table 3. In the dynamic autoregressive model (6) the autoregressive coefficient $\alpha_{1}$ is not statistically significant. On the other hand, the "pure" autoregressive model (7) yields also good in-sample predictions with the relatively high and strongly statistically significant autoregressive coefficient $\alpha_{1}$. The statistical improvement compared with the static model (4) is highly statistically significant.

In the autoregressive interaction model (8) it seems reasonable to select $a=1$, that is $y_{t-1}$, in the interaction term which is statistically significant with the U.S. term spread $\left(S P_{t}^{U S}\right)$ producing evidence that the U.S. term spread has asymmetric effect on the recession probability depending on the state of the economy. In this model, the pure first lag of the dependent variable $y_{t-1}$ is excluded because when it is included in the model, the estimate for the $\gamma$ is statistically insignificant and the model reduces to the dynamic model (5) or the dynamic autoregressive model (6), depending on the value of the autoregressive parameter $\alpha_{1}$. One important feature in these autoregressive models (7) and (8) with statistically significant coefficient for the $\alpha_{1}$ is that the longer history of explanatory variables is also taken into account in a parsimonious way. This thing can especially improve the predictive ability of volatile stock market returns as a predictive variable.

In Germany the values of the pseudo- $R^{2}$ in all dynamic models in Table 4 are 
even higher than in the U.S. The autoregressive interaction model (8) yields the best in-sample predictions. Interestingly the U.S. term spread has asymmetric effects also in the case of Germany. In fact, the interaction term is not statistically significant when the domestic German term spread is examined in the interaction term. In the dynamic autoregressive model, the coefficient for the $y_{t-1}^{G E}$ is not, but $\alpha_{1}$ for $\pi_{t-1}$ is, statistically significant indicating, as in the U.S., that this model is perhaps not the best one.

As an example of in-sample recession predictions, Figures 3 and 4 show the recession probabilities of the static model and the autoregressive model which are the first and the fourth models in Tables 3 and 4. In out-of-sample forecasting, as discussed in Section 3, the variable $y_{t-1}$ is not observed at the time of forecasting $t-h$, when $h>1$. Therefore, we present the predictions of the in-sample models which are fully comparable with the out-of-sample forecasts presented in the next section.

In the static model, the domestic term spread is the only predictive variable, but in the autoregressive model all the experimented explanatory variables are included. It can be seen that in the autoregressive model the recession probability matches better the realized values of the recession indicator. A relatively high and positive autoregressive coefficient for the $\pi_{t-1}$ and employed additional explanatory variables appears to be useful. In recession periods, the recession probabilities are also higher in the autoregressive model. When the economy is in an expansionary state, the recession probability is constantly higher in the static model whereas in the autoregressive model it is very close to zero, as it should be.

\subsection{Out-of-Sample Forecasting Results}

The in-sample evidence shows a good deal of predictability for recession periods in the U.S and Germany. However, in-sample predictability will not necessarily mean outof-sample predictability. For example, Estrella and Mishkin (1998) show that in the case of the static probit model and U.S. recession periods, some of the best in-sample predictive models perform quite poorly out-of-sample.

In this study, the first out-of-sample predictions are made for January 1995. The sample period thus contains the recession period that began in both countries in 2001 . 
In other months, the economy is an expansionary state. If, for example, the forecast horizon is 10 months, $h=10$, then the values of the explanatory variables are known up to 1994 M12 when the forecast for January 1995 is made. However, because of the assumed nine-month publication lag in the recession indicator, the estimation period is 1972 M1-1994 M2 (cf. Kauppi and Saikkonen, 2007). Further, the parameters in the probit models are estimated recursively. After adding one month to the previous estimation period and re-estimating the parameters, a forecast for the next month is calculated. This procedure is repeated recursively until the end of the forecast sample. The last out-of-sample forecasts are made for March 2007.

In out-of-sample forecasting results in Tables $5-8$, the same forecasting models as in the in-sample analysis are employed. Thus the variables included in the explanatory variables vectors are

$$
\begin{aligned}
\boldsymbol{x}_{t-k}^{U S} & =\left(\begin{array}{lllll}
S P_{t-6}^{U S}, & S P_{t-6}^{G E}, & r_{t-2}^{U S}, & r_{t-4}^{U S}, & r_{t-6}^{U S}
\end{array}\right), \\
\boldsymbol{x}_{t-k}^{G E} & =\left(\begin{array}{llllll}
S P_{t-6}^{G E}, & S P_{t-6}^{U S}, & r_{t-3}^{G E}, & r_{t-6}^{G E}, & r_{t-9}^{G E}, & I S_{t-6}
\end{array}\right),
\end{aligned}
$$

where the lag orders are the same as the in-sample model selection suggested in the previous section. The predictive models in which the foreign term spread is excluded is also examined. In this case, the vectors of the explanatory variables are denoted by $\boldsymbol{x}_{t-k}^{U S *}$ and $\boldsymbol{x}_{t-k}^{G E *}$. When the domestic term spread is the only predictor, then the vectors are $\boldsymbol{v}_{t-k}^{U S}$ and $\boldsymbol{v}_{t-k}^{G E}{ }^{9}$

When the forecast horizon $h$ lengthens, the lags of explanatory variables should be tailored so that only the information included in the information set $\Omega_{t-h}$ at forecast time $t-h$ is used. For example, when the forecast horizon is 16 months meaning that we are interested in forecasting the seven month $\left(h^{f}=7\right)$ ahead value of the recession indicator, then in the predictive models for the U.S., the vector $\boldsymbol{x}_{t-k}^{U S}$ contains the following variables

$$
\boldsymbol{x}_{t-k}^{U S}=\left(S P_{t-7}^{U S}, \quad S P_{t-7}^{G E}, \quad r_{t-7}^{U S}\right)
$$

Forecast accuracy is evaluated with the out-of-sample pseudo- $R^{2}$ (Estrella, 1998). In addition, the recession probabilities are also classified to construct different reces-

\footnotetext{
${ }^{9}$ The lag orders of explanatory variables in these two cases are the same as above in $\boldsymbol{x}_{t-k}^{U S}$ and $\boldsymbol{x}_{t-k}^{G E}$.
} 
sion signals. In this classification process, 50 and 25 percent thresholds are used to classify the recession probabilities as "strong", "weak" or "no" recession signals. For example, if the recession probability is between 25 and 50 percent, the model gives a "weak" recession signal. In this classification the asymmetric forecasting point scheme (cf. Dueker, 2002) presented in Table 2 is applied, which puts greater emphasis on the right forecasts. It also prefers a false recession alarm compared to a missed recession month. The rationale behind this is that, for example, firms or policymakers are willing to take a "recession insurance" and accept a possible false alarm rather than be caught by an unexpected recession.

Tables 5 and 6 show the out-of-sample forecasting performance of the employed models in the U.S. As discussed in Section 3, the most interesting forecasts are for the future values of the recession indicator. Therefore, the results from shorter horizons, $h \leq 9$, are available upon request. It is worth noting that in models where iterative forecasts are considered, it is computationally too demanding to repeat the iterative forecasts for the longest forecast horizon of 21 months. ${ }^{10}$ Therefore only the static model (4) and the autoregressive model (7) are considered in those cases.

The best employed models yield accurate out-of-sample forecasts for the state of the economy in the U.S. and, especially, for the beginning and the end of the recession period starting in the year 2001. According to the values of the out-of-sample-ps $R^{2}$ and the forecasting points the highest predictive accuracy and the maximal forecast horizon is obtained when the horizon is about 15 months, which is the same as $h^{f}=6$. At this forecast horizon, the the autoregressive model (7) and the autoregressive model with the interact term (8) outperform the iterative forecasts from the dynamic model (5) yielding the best out-of-sample forecasts with the explanatory variables included in the vector $\boldsymbol{x}_{t-k}^{U S}$. In fact, the autoregressive interaction model is even the best model when the forecast horizon is between 12 to 16 months, giving evidence that there is asymmetric predictive content in the U.S. term spread depending on the current state of the economy in out-of-sample forecasts as well.

The models with the U.S. stock returns $\left(\boldsymbol{x}_{t-k}^{U S *}\right)$ and the models with also a foreign German term spread $\left(\boldsymbol{x}_{t-k}^{U S}\right)$ outperform the models with only the U.S. term spread

\footnotetext{
${ }^{10}$ In iterative forecasts, it means that $2^{21}$ different paths should be calculated before the forecast.
} 
$\left(\boldsymbol{v}_{t-k}^{U S}\right)$ across all probit models and forecast horizons. Thus these additional financial variables have predictive content also in the out-of-sample predictions for the U.S. recessions.

Comparing the horizon-specific direct and iterative forecasts from the dynamic model (5), the in-sample evidence that the iterative forecasting models based on the $y_{t-1}$ outperform the direct forecasts from the static or in the dynamic model with the horizon-specific $y_{t-h}$ can be confirmed. In addition, as in Table 3, the autoregressive coefficient $\alpha_{1}$ is in most cases statistically insignificant in the dynamic autoregressive model (6). This model thus reduces to the dynamic model (5), and its out-of-sample predictions are almost the same as in the dynamic model. ${ }^{11}$ Further, when the forecast horizon is 21 months, which is the longest horizon considered, the static model turns out to be an adequate model without any dynamics in the model equation. However, in this forecast horizon also, the considered additional explanatory variables have useful predictive power.

Figure 5 illustrates the out-of-sample performance of U.S. recession prediction models when the forecast horizon is 15 months. These four models are highlighted in Tables 5 and 6 . The depicted forecasts indicate that the considered three dynamic models certainly have the predictive power to forecast the beginning and the end of the latest recession in 2001. The static model, where the U.S. term spread is the single predictive variable, tends to produce significantly higher false recession probability in the expansionary period compared with the dynamic models. In the dynamic models the recession signals at the recession period are also more distinct with higher recession probabilities. Kauppi and Saikkonen (2007) and Kauppi (2008) stressed these same phenomena but, contrary to their findings, in this study the autoregressive models (7) and (8) seem to generate somewhat better out-of-sample forecasts compared with the iterative forecasts from the dynamic model (5). The predictive power of the considered additional financial variables with the domestic term spread is the main reason for this finding.

\footnotetext{
11 Therefore, Tables 5-6 only report the results from the dynamic iterative model (5). The same is with the static model (4) which yield almost the same or even better predictions as the dynamic direct model (cf. equation (13) with $\alpha_{1}=0$ ) since the coefficient for $y_{t-h}$ is statistically insignificant for longer horizons $h$.
} 
In the case of Germany, it is important to note that the latest recession period lasted considerably longer than the recession in the U.S. as in Germany, the recession ended in August 2003. Nevertheless, it can be seen that the essential conclusions between different predictive models are parallel to predictive performance in the case of the U.S. However, due to the fact that the term spreads rode up immediately after the recession began (see Figure 1) it appears inevitable that the recession probability would decrease midstream in the recession period. Thus the out-of-sample pseudo- $R^{2}$ values are even negative in some models in Table 7 . Therefore the forecasting points in different models presented in Table 8 are the main model evaluation measure.

As in the U.S. it turns out that the dynamic iterative forecasts from the dynamic model (5) are more accurate than the forecasts from the static model, and when the forecast horizon increases towards 15 or 16 months the autoregressive models (7) and (8) seem to outperform the alternative models. The evidence reflects that the interest rate differential and German stock returns clearly have additional predictive power also out-of-sample with the German term spread in all models (models with $\boldsymbol{x}_{t-k}^{G E *}$ ). Interestingly, the U.S. term spread, which is a statistically significant predictor insample, seems to be a quite poor predictive variable since the forecasting results are much better without it. The statistical significance of the interest rate differential, however, suggests that the U.S. monetary policy has an impact on the recession probability in Germany via the short-term interest rate $r_{t}^{U S}$ even though the U.S. term spread is excluded from the predictive models.

It is interesting that the autoregressive interaction model (8) with the asymmetric effects of the U.S. term spread $S P_{t}^{U S}$ seems to outperform the interaction model with asymmetric effects on the German term spread when the explanatory variables in vector $\boldsymbol{x}_{t-k}^{G E}$ are examined. Nevertheless, when the U.S. term spread is excluded from the model, the asymmetric effect of the German term spread in the autoregressive interaction model has, on average, only marginal additional predictive power compared with the corresponding autoregressive model.

Figure 6 depicts the out-of-sample predictions of different models when the examined forecast horizon is 15 months. In the first, traditional static predictive model with only the domestic German term spread, the recession probability is very low 
during the recession period and the overall forecasting performance is quite disappointing compared with the dynamic models with additional explanatory variables. The recession probability indeed falls off during the recession period in all dynamic models. However, the models manage to predict the start and the end of the recession period quite well. As in the U.S. in the year 1999, the recession probability increased but at that time there was no recession.

An other way to examine the likelihood of recession is obtained from the hitting probabilities introduced by Chauvet and Potter (2005) and Kauppi and Saikkonen (2007) who defined hitting probability of an economy being hit by a recession in a particular month. In recession forecasting the probability of continued expansion, which means a time period where the economy is in an expansionary state every month, is particularly of interest. This is the complement probability of the cumulative distribution where the hitting probabilities of individual months are calculated.

The evidence from the continued expansion probabilities of different expansionary and recessionary periods is the same as above in month-to-month prediction. The comparison between different models appears to depend on the state of the economy. Using the static probit model, the recession probability appears to deviate significantly from zero in expansionary periods, as seen for instance in Figures 5 and 6. In dynamic models the probabilities are more close to zero in expansionary periods. Therefore during in expansionary periods the static model seems to overestimate the probability of recession. On the other hand, in recession periods the dynamic model (5) with iterative forecasts constantly gives the highest probabilities of continued expansion. ${ }^{12}$ Therefore, according to the continued expansion probabilities as well, the autoregressive probit models (7) and (8) with domestic term spread and other explanatory variables in a corresponding countries' yield the best predictions.

\subsection{Recession Probabilities in 2007 and 2008}

Although the last and the future values of the recession indicator are unknown at the end of the sample period, it is interesting to construct recession forecasts for those months. In this section, we consider recession forecasts up to June 2008. Early in

\footnotetext{
12 Further details of continued expansion probabilities are available upon request.
} 
2008, there was a great deal of uncertainty regarding the state of the U.S. economy. The U.S. term spread has been low and even negative for quite a long time in 2007, indicating a higher recession risk than at any time since the latest recession in 2001 . At the same time in Germany, it seems that the expansionary period is still continuing.

The estimated recession forecasts and corresponding continued expansion probabilities at this 15-month time period are shown in Table 9 . The forecast horizon is 15 months and thus the latest forecasts for June 2008 are based on the information from December 2007. In the U.S., the recession probabilities are higher than 25 percent in most of the latest months in all models. In the autoregressive interaction model the forecast is higher than a 50 percent threshold value after August 2007.

In the case of Germany, the forecasts are quite high if the U.S. term spread is included in the models. Nevertheless, as was found in the out-of-sample forecasts, the forecasting power of the U.S. term spread in Germany is questionable. If it is withdrawn from the forecasting models, then the probability forecasts are clearly lower than with it. The best out-of-sample dynamic models proposed in the previous section, in which the U.S. term spread is excluded, indicate that the recession probabilities are increasing in the latest months considered.

On the whole, the recession risk appears to be higher than at any time since the last recession in both countries.

\section{Conclusions}

This paper has examined the performance of recession prediction models which are based on the dynamic probit models and a number of financial explanatory variables. Following the evidence in previous studies, the term spread is found a useful predictive variable for the U.S. and German recessions. However, according to the results presented here, stock market returns have additional predictive power to forecast recession periods in both countries using different probit models and the predictive information is distributed in many lagged stock returns. The short-term interest rate differential between the United States and Germany also has substantial predictive content in terms of both in-sample and out-of-sample predictions to predict German 
recession. The same is true with the foreign German term spread in forecasting the U.S. recessions. In addition the U.S. term spread is also a statistically significant predictor in the case of Germany but its out-of-sample predictive content appears to be poor in the last recession period.

Based on the comparisons between different probit models, the results indicate that statistically significant additional predictive content is obtained by allowing for dynamic structures in the predictive model compared with the traditional static model used in many previous studies. Especially, the probit models with statistically significant autoregressive structure in model equation performed somewhat better outof-sample than the static and other dynamic models. Especially, the experimented autoregressive interaction model where the U.S. term spread have an asymmetric effect on recession probability depending the state of the economy, provide accurate forecasts for the recession periods in the U.S and Germany.

\section{References}

Akaike, H. (1974): A new look at statistical model identification. IEEE Transactions on Automatic Control, 19, 713-723.

Bernard, H., and Gerlach, S. (1998): Does the term structure predict recessions? The international evidence. International Journal of Finance and Economics, 3, 195-215.

Boulier, B. L., and Steckler, H. O. (2000): The term spread as a monthly cyclical indicator. Economics Letters, 66, 79-83.

Chauvet, M., and Potter, S. (2005): Forecasting recession using the yield curve. Journal of Forecasting, 24(2), 77-103.

Davis, E. P., and Fagan, G. (1997): Are financial spreads useful indicators of future inflation and output growth in EU countries? Journal of Applied Econometrics, 12, $701-714$. 
de Jong, R. M., and Woutersen, T. M. (2007): Dynamic time series binary choice. Economics Working Paper Archive, 538. The Johns Hopkins University, Department of Economics. Available at http://www.econ.jhu.edu/pdf/papers/WP538.pdf.

Diebold, F. X., and Rudebusch, G. D. (1989): Scoring the leading indicators. Journal of Business, 62(3), 369-391.

Dueker, M. J. (1997): Strengthening the case for the yield curve as a predictor of U.S. recessions. Federal Reserve Bank of St.Louis Review, 79, 41-51.

Dueker, M. J. (2002): Regime-dependent recession forecasts and the 2001 recession. Federal Reserve Bank of St.Louis Review, 84, 29-36.

Dueker, M. J. (2005): Dynamic forecasts of qualitative variables: A qual VAR model of U.S. recessions. Journal of Business and Economic Statistics, 23(1), 96-104.

Estrella, A. (1998): A new measure of fit for equations with dichotomous dependent variables. Journal of Business and Economic Statistics, 16, 198-205.

Estrella, A. (2005a): The yield curve as a leading indicator: Frequently asked questions. Federal Reserve Bank of New York. Available at http:/www.newyorkfed.org/research/ capital_markets/ycfaq.pdf.

Estrella, A. (2005b): Why does the yield curve predict output and inflation? The Economic Journal, 115, 722-744.

Estrella, A., and Hardouvelis, G. A. (1991): The term structure as a predictor of real economic activity. Journal of Finance, 46, 555-576. 
Estrella, A., and Mishkin, F. S. (1998): Predicting U.S. recessions: Financial variables as leading indicators. Review of Economics and Statistics, 80(1), 45-61.

Estrella, A., and Rodrigues, A. P. (1998): Consistent covariance matrix estimation in probit models with autocorrelated disturbances. Federal Reserve Bank of New York Staff Reports, 39.

Estrella, A., Rodrigues, A. P., and Schich, S. (2003): How stable is the predictive power of the yield curve: Evidence from Germany and the United States. Review of Economics and Statistics, 85, 629-644.

Fama, E. F. (1990): Stock returns, expected returns, and real activity. Journal of Finance, 45, 1089-1108.

Florio, A. (2004): The asymmetric effects of monetary policy. Journal of Economic Surveys, 84(2), 409-426.

Kauppi, H. (2008): Yield-Curve Based Probit Models for Forecasting U.S. Recessions: Stability and Dynamics. HECER Discussion Paper, 221. Helsinki Center of Economic Research.

Kauppi, H., and Saikkonen, P. (2007): Predicting U.S. recessions with dynamic binary response models. Review of Economics and Statistics, forthcoming.

Marcellino, M., Stock J. H., and Watson, M. W. (2006): A comparison of direct and iterated AR methods for forecasting macroeconomic time series. Journal of Econometrics, 135, 499-526.

Moneta, F. (2003): Does the yield spread predict recessions in the Euro area? ECB working paper, 294. 
Morgan, D. P. (1993): Asymmetric effects of monetary policy. Federal Reserve Bank of Kansas City Economic Review, 21-33.

Romer, D. (2001): Advanced Macroeconomics. Second edition. McGraw-Hill, New York.

Rydberg, T., and Shephard, N. (2003): Dynamics of trade-by-trade price movements: Decomposition and models. Journal of Financial Econometrics, 1, 2-25.

Schwarz, G. (1978): Estimating the dimension of a model. Annals of Statistics, 6, 461-464.

Stock, J. H., and Watson, M. W. (2003): Forecasting output and inflation: The role of asset prices. Journal of Economic Literature, 41, 788-829.

Valckx, N., de Ceuster, M. J. K., and Annaert, J. (2002): Is financial market volatility informative to predict recessions? DNB Staff Report, 93.

Wright, J. H. (2006): The yield curve and predicting recessions. Finance and Economics Discussion Series, 2006-2007. Board of Governors of the Federal Reserve System. 


\section{Appendix: Data set}

\section{Recession periods}

$y_{t}^{U S}$ : Recession periods defined by the National Bureau of Economic Research (NBER), http://www.nber.org/cycles/cyclesmain.

$y_{t}^{G E}$ : Recession periods defined by the Economic Cycle Research Institute (ECRI), http://www.businesscycle.com.

\section{Interest rates}

United States: http://www.federalreserve.gov/releases/h15/data.

$i_{t}^{U S}$ : Three-month U.S. Treasury Bill rate, secondary market.

$R_{t}^{U S}$ : Ten-year Treasury Bond rate, constant maturity.

Germany: http://www.bundesbank.de/statistik/statistik.

$i_{t}^{G E}$ : Three-month money market rate (series su0107).

$R_{t}^{G E}$ : Ten-year Federal security (series WZ9826). [Note: The missing values between 1971 M1-1972 M9 are replaced by the OECD 10-year interest rate.]

\section{Stock returns}

Log-differences of real stock indices (deflated by the consumer price index)

$$
r_{t}=100\left(\log \text { stockinde } x_{t}-\log \text { stockinde }_{t-1}\right) \text {. }
$$

United States $r_{t}^{U S}$ : S\&P 500 index, http://www.yahoo.finance.com and http://www.econstats.com.

Germany $r_{t}^{G E}$ : German MSCI index (Morgan Stanley International Capital), http://www.mscibarra.com. 
Table 1: Descriptive sample statistics and correlations.

\begin{tabular}{cccccc}
\hline \hline & $S P_{t}^{U S}$ & $S P_{t}^{G E}$ & $I S_{t}$ & $r_{t}^{U S}$ & $r_{t}^{G E}$ \\
\hline $\min$ & -2.65 & -5.15 & -7.27 & -24.80 & -27.81 \\
$\max$ & 4.42 & 5.11 & 5.56 & 14.12 & 20.49 \\
average & 1.60 & 1.22 & 0.26 & 0.24 & 0.29 \\
standard dev. & 1.32 & 1.77 & 2.52 & 4.49 & 5.65 \\
\hline correlations & $S P_{t}^{U S}$ & $S P_{t}^{G E}$ & $I S_{t}$ & $r_{t}^{U S}$ & $r_{t}^{G E}$ \\
$S P^{U S}$ & 1 & - & - & - & - \\
$S P^{G E}$ & 0.33 & 1 & - & - & - \\
$I S$ & -0.27 & 0.51 & 1 & - & - \\
$r^{U S}$ & 0.10 & 0.08 & 0.03 & 1 & - \\
$r^{G E}$ & 0.03 & 0.07 & 0.08 & 0.53 & 1 \\
\hline \hline
\end{tabular}

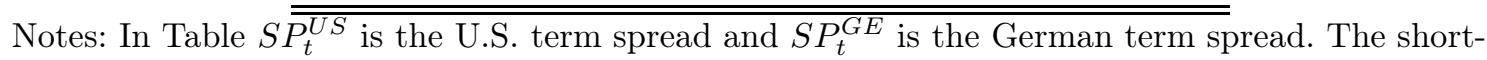
term interest rate differential is denoted by $I S_{t}$. The U.S. stock return is denoted by $r_{t}^{U S}$ and $r_{t}^{G E}$ is the German stock return, respectively. The number of observations $T$ is 444 .

Table 2: Forecast points for different outcomes.

\begin{tabular}{c|c|cc}
\hline \hline signal & & $\begin{array}{c}y_{t}=1 \\
\text { recession }\end{array}$ & $\begin{array}{c}y_{t}=0 \\
\text { expansion }\end{array}$ \\
\hline strong recession signal & $\hat{p}_{t} \geq 0.50$ & 1 & -1 \\
weak recession signal & $0.25 \leq \hat{p}_{t}<0.50$ & $1 / 2$ & 0 \\
no recession signal & $\hat{p}_{t}<0.25$ & -1 & $1 / 2$ \\
\hline \hline
\end{tabular}

Note: Individual "points" of possible outcomes according to recession signals and the values of recession indicator. 
Table 3: In-sample results for recession periods in the United States.

\begin{tabular}{|c|c|c|c|c|c|c|}
\hline model & static & static & dyn.iter & auto. & dyn.auto. & auto.int \\
\hline \multirow[t]{2}{*}{$\omega$} & -0.26 & -0.54 & -0.17 & -0.11 & -2.37 & -0.06 \\
\hline & $(0.24)$ & $(0.28)$ & $(0.03)$ & $(0.09)$ & $(0.46)$ & $(0.08)$ \\
\hline \multirow[t]{2}{*}{$S P_{t-6}^{U S}$} & -0.61 & -0.42 & -0.41 & -0.15 & -0.51 & -0.32 \\
\hline & $(0.13)$ & $(0.13)$ & $(0.14)$ & $(0.04)$ & $(0.20)$ & $(0.09)$ \\
\hline \multirow[t]{2}{*}{$S P_{t-6}^{G E}$} & & -0.38 & -0.31 & -0.11 & -0.31 & -0.07 \\
\hline & & $(0.09)$ & $(0.09)$ & $(0.04)$ & $(0.11)$ & $(0.05)$ \\
\hline \multirow[t]{2}{*}{$r_{t-2}^{U S}$} & & -0.05 & -0.12 & -0.13 & -0.12 & -0.16 \\
\hline & & $(0.02)$ & $(0.02)$ & $(0.03)$ & $(0.03)$ & $(0.04)$ \\
\hline \multirow[t]{2}{*}{$r_{t-4}^{U S}$} & & -0.10 & -0.17 & -0.08 & -0.17 & -0.08 \\
\hline & & $(0.02)$ & $(0.03)$ & $(0.02)$ & $(0.03)$ & $(0.03)$ \\
\hline \multirow[t]{2}{*}{$r_{t-6}^{U S}$} & & -0.08 & -0.07 & -0.05 & -0.07 & -0.02 \\
\hline & & $(0.03)$ & $(0.04)$ & $(0.03)$ & $(0.06)$ & $(0.03)$ \\
\hline \multirow[t]{2}{*}{$\pi_{t-1}$} & & & & 0.79 & -0.13 & 0.80 \\
\hline & & & & $(0.03)$ & $(0.21)$ & $(0.03)$ \\
\hline \multirow[t]{2}{*}{$y_{t-1}^{U S}$} & & & 3.88 & & 4.55 & \\
\hline & & & $(0.53)$ & & $(0.90)$ & \\
\hline \multirow[t]{2}{*}{$y_{t-1}^{U S} S P_{t-6}^{U S}$} & & & & & & 0.47 \\
\hline & & & & & & $(0.12)$ \\
\hline $\log -\mathrm{L}$ & -84.64 & -58.93 & -16.99 & -28.88 & -16.79 & -28.22 \\
\hline$p s R^{2}$ & 0.29 & 0.49 & 0.83 & 0.73 & 0.84 & 0.74 \\
\hline$A I C$ & 86.64 & 64.93 & 23.99 & 35.88 & 24.79 & 36.22 \\
\hline$B I C$ & 90.26 & 75.79 & 36.66 & 48.55 & 39.27 & 50.70 \\
\hline$Q P S$ & 0.19 & 0.13 & 0.04 & 0.07 & 0.04 & 0.07 \\
\hline $50 \%$ & 0.89 & 0.90 & 0.98 & 0.95 & 0.97 & 0.96 \\
\hline $25 \%$ & 0.81 & 0.89 & 0.97 & 0.94 & 0.97 & 0.93 \\
\hline
\end{tabular}

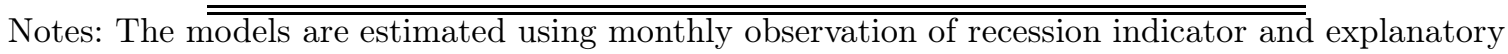
variables from 1972 M1 to 1994 M12. Robust standard errors (see equation (11)) are reported in parentheses. In the Table, $p s R^{2}$ reflects the pseudo- $R^{2}, A I C$ and $B I C$ the values of the Akaike (1974) and Scwartz (1978) information criteria, QPS is the quadratic probability score (Diebold and Rudebusch, 1989) and 50\% and 25\% mean the ratio of correct predictions with 50 and 25 percent threshold values in the classification of recession probabilities. 
Table 4: In-sample results for recession periods in Germany.

\begin{tabular}{|c|c|c|c|c|c|c|}
\hline & static & static & dyn.iter & auto. & dyn.auto. & auto.int \\
\hline \multirow[t]{2}{*}{$\omega$} & 0.13 & 0.66 & -0.17 & 0.69 & 0.09 & 1.72 \\
\hline & $(0.22)$ & $(0.38)$ & $(0.07)$ & $(0.22)$ & $(0.34)$ & $(0.93)$ \\
\hline \multirow[t]{2}{*}{$S P_{t-6}^{U S}$} & & -0.55 & -2.67 & -0.56 & -1.10 & -2.53 \\
\hline & & $(0.20)$ & $(0.78)$ & $(0.19)$ & $(0.68)$ & $(0.68)$ \\
\hline \multirow[t]{2}{*}{$S P_{t-6}^{G E}$} & -0.95 & -0.94 & -0.67 & -0.47 & -0.46 & -0.70 \\
\hline & $(0.16)$ & $(0.21)$ & $(0.28)$ & $(0.13)$ & $(0.14)$ & $(0.45)$ \\
\hline \multirow[t]{2}{*}{$r_{t-3}^{G E}$} & & 0.01 & 0.04 & -0.08 & -0.06 & -0.15 \\
\hline & & $(0.02)$ & $(0.04)$ & $(0.03)$ & $(0.05)$ & $(0.06)$ \\
\hline \multirow[t]{2}{*}{$r_{t-6}^{G E}$} & & -0.04 & -0.17 & -0.10 & -0.18 & -0.45 \\
\hline & & $(0.03)$ & $(0.07)$ & $(0.05)$ & $(0.06)$ & $(0.22)$ \\
\hline \multirow[t]{2}{*}{$r_{t-9}^{G E}$} & & -0.06 & -0.23 & -0.25 & -0.35 & -0.73 \\
\hline & & $(0.03)$ & $(0.07)$ & $(0.06)$ & $(0.15)$ & $(0.23)$ \\
\hline \multirow[t]{2}{*}{$I S_{t-6}$} & & -0.27 & -0.79 & -0.26 & -0.44 & -0.80 \\
\hline & & $(0.10)$ & $(0.23)$ & $(0.08)$ & $(0.22)$ & $(0.21)$ \\
\hline \multirow[t]{2}{*}{$\pi_{t-1}$} & & & & 0.80 & 0.64 & 0.77 \\
\hline & & & & $(0.01)$ & $(0.10)$ & $(0.03)$ \\
\hline \multirow[t]{2}{*}{$y_{t-1}^{G E}$} & & & 7.48 & & 2.38 & \\
\hline & & & $(1.35)$ & & $(1.76)$ & \\
\hline \multirow[t]{2}{*}{$y_{t-1}^{G E} S P_{t-6}^{U S}$} & & & & & & 1.65 \\
\hline & & & & & & $(0.48)$ \\
\hline $\log -\mathrm{L}$ & -72.14 & -54.26 & -11.98 & -12.56 & -7.65 & -1.37 \\
\hline$p s R^{2}$ & 0.69 & 0.78 & 0.97 & 0.97 & 0.98 & 0.99 \\
\hline$A I C$ & 74.14 & 61.26 & 19.98 & 20.56 & 16.65 & 10.37 \\
\hline$B I C$ & 77.76 & 73.93 & 34.46 & 35.04 & 32.94 & 26.66 \\
\hline$Q P S$ & 0.16 & 0.13 & 0.03 & 0.03 & 0.02 & 0.01 \\
\hline $50 \%$ & 0.71 & 0.90 & 0.98 & 0.98 & 0.99 & 1.00 \\
\hline $25 \%$ & 0.70 & 0.89 & 0.97 & 0.97 & 0.99 & 1.00 \\
\hline
\end{tabular}

Notes: See notes to Table 3. 
Table 5: Out-of-sample pseudo- $R^{2}$ values of employed predictive models in the United States.

\begin{tabular}{cccccccccc}
\hline \hline & $h$ & 10 & 11 & 12 & 13 & 14 & 15 & 16 & 21 \\
model & $h^{f}$ & 1 & 2 & 3 & 4 & 5 & 6 & 7 & 12 \\
\hline static (4); $\boldsymbol{x}_{t-k}^{U S}$ & 0.34 & 0.34 & 0.29 & 0.31 & 0.28 & 0.28 & 0.28 & 0.30 \\
dyn.iter (5), $\boldsymbol{x}_{t-k}^{U S}$ & 0.52 & 0.54 & 0.51 & 0.51 & 0.39 & $\mathbf{0 . 3 9}$ & 0.39 & - \\
auto (7); $\boldsymbol{x}_{t-k}^{U S}$ & 0.49 & 0.48 & 0.48 & 0.48 & 0.47 & $\mathbf{0 . 4 7}$ & 0.46 & 0.29 \\
auto.int (8); $\boldsymbol{x}_{t-k}^{U S}, S P^{U S}$ & 0.37 & 0.34 & 0.53 & 0.53 & 0.55 & $\mathbf{0 . 5 5}$ & 0.55 & - \\
\hline static (4); $\boldsymbol{v}_{t-k}^{U S}$ & 0.09 & 0.09 & 0.09 & 0.08 & 0.08 & $\mathbf{0 . 0 9}$ & 0.14 & 0.19 \\
dyn.iter (5), $\boldsymbol{v}_{t-k}^{U S}$ & 0.26 & 0.26 & 0.26 & 0.26 & 0.26 & 0.26 & 0.25 & - \\
auto (7); $\boldsymbol{v}_{t-k}^{U S}$ & 0.28 & 0.28 & 0.28 & 0.28 & 0.28 & 0.28 & 0.27 & 0.18 \\
auto.int (8); $\boldsymbol{v}_{t-k}^{U S}, S P^{U S}$ & 0.33 & 0.32 & 0.31 & 0.31 & 0.30 & 0.30 & 0.25 & - \\
\hline static (4); $\boldsymbol{x}_{t-k}^{U S *}$ & 0.21 & 0.21 & 0.18 & 0.18 & 0.12 & 0.12 & 0.17 & 0.19 \\
dyn.iter (5), $\boldsymbol{x}_{t-k}^{U S *}$ & 0.45 & 0.47 & 0.43 & 0.42 & 0.28 & 0.28 & 0.27 & - \\
auto (7); $\boldsymbol{x}_{t-k}^{U S *}$ & 0.44 & 0.44 & 0.41 & 0.41 & 0.40 & 0.40 & 0.36 & 0.16 \\
auto.int (8); $\boldsymbol{x}_{t-k}^{U S *}, S P^{U S}$ & 0.25 & 0.22 & 0.42 & 0.41 & 0.45 & 0.45 & 0.38 & - \\
\hline \hline
\end{tabular}

Notes: The out-of-sample values of pseudo- $R^{2}$ suggested by Estrella (1998). The probit model is denoted at the left with the explanatory variables included in the model. In the autoregressive interaction model (8), the term spread that is used in the interaction term is also mentioned. In the dynamic iterative forecasts (5) and in the autoregressive interaction model (8) the first lagged value of the recession indicator $y_{t-1}$ is used. 
Table 6: Out-of-sample forecasting points of employed predictive models in the United States.

\begin{tabular}{|c|c|c|c|c|c|c|c|c|c|}
\hline & $h$ & 10 & 11 & 12 & 13 & 14 & 15 & 16 & 21 \\
\hline model & $h^{f}$ & 1 & 2 & 3 & 4 & 5 & 6 & & 12 \\
\hline $\operatorname{static}(4) ; \boldsymbol{x}_{t-k}^{U S}$ & & 0.82 & 0.82 & 0.82 & 0.78 & 0.82 & 0.82 & 0.82 & 0.78 \\
\hline dyn.iter (5), $\boldsymbol{x}_{t-k}^{U S}$ & & 0.86 & 0.87 & 0.88 & 0.88 & 0.81 & 0.81 & 0.81 & - \\
\hline $\operatorname{auto}(7) ; \boldsymbol{x}_{t-k}^{U S}$ & & 0.84 & 0.84 & 0.85 & 0.85 & 0.85 & 0.85 & 0.85 & 0.78 \\
\hline auto.int (8); $\boldsymbol{x}_{t-k}^{U S}, S P^{U S}$ & & 0.84 & 0.83 & 0.87 & 0.87 & 0.91 & 0.91 & 0.90 & - \\
\hline $\operatorname{static}(4) ; \boldsymbol{v}_{t-k}^{U S}$ & & 0.67 & 0.67 & 0.67 & 0.66 & 0.66 & 0.67 & 0.70 & 0.76 \\
\hline dyn.iter (5), $\boldsymbol{v}_{t-k}^{U S}$ & & 0.82 & 0.82 & 0.82 & 0.82 & 0.83 & 0.82 & 0.82 & - \\
\hline $\operatorname{auto}(7) ; \boldsymbol{v}_{t-k}^{U S}$ & & 0.80 & 0.80 & 0.80 & 0.80 & 0.80 & 0.80 & 0.79 & 0.71 \\
\hline auto.int (8); $\boldsymbol{v}_{t-k}^{U S}, S P^{U S}$ & & 0.79 & 0.78 & 0.77 & 0.77 & 0.76 & 0.76 & 0.73 & - \\
\hline $\operatorname{static}(4) ; \boldsymbol{x}_{t-k}^{U S *}$ & & 0.79 & 0.79 & 0.77 & 0.77 & 0.75 & 0.75 & 0.78 & 0.75 \\
\hline dyn.iter $(5), \boldsymbol{x}_{t-k}^{U S *}$ & & 0.84 & 0.84 & 0.86 & 0.86 & 0.85 & 0.85 & 0.84 & - \\
\hline $\operatorname{auto}(7) ; \boldsymbol{x}_{t-k}^{U S *}$ & & 0.82 & 0.82 & 0.82 & 0.82 & 0.85 & 0.85 & 0.85 & 0.68 \\
\hline auto.int (8); $\boldsymbol{x}_{t-k}^{U S *}, S P^{U S}$ & & 0.83 & 0.83 & 0.85 & 0.83 & 0.85 & 0.85 & 0.80 & - \\
\hline
\end{tabular}

Notes: Forecasting points are obtained from the point scheme presented in Table 2 by dividing the sum of individual points by the number of maximum points which means that the state of the economy is predicted correctly in every month. 
Table 7: The out-of-sample values of $p s R^{2}$ of employed models in Germany.

\begin{tabular}{|c|c|c|c|c|c|c|c|c|c|}
\hline & $h$ & 10 & 11 & 12 & 13 & 14 & 15 & 16 & 21 \\
\hline model & $h^{f}$ & 1 & 2 & 3 & 4 & 5 & 6 & 7 & 12 \\
\hline $\operatorname{static}(4) ; \boldsymbol{x}_{t-k}^{G E}$ & & 0.07 & 0.03 & 0.00 & neg & neg & neg & neg & 0.14 \\
\hline dyn.iter $(5), \boldsymbol{x}_{t-k}^{G E}$ & & neg & neg & neg & neg & neg & neg & neg & - \\
\hline $\operatorname{auto}(7) ; \boldsymbol{x}_{t-k}^{G E}$ & & 0.35 & 0.36 & 0.37 & neg & neg & 0.02 & neg & 0.16 \\
\hline auto.int (8); $\boldsymbol{x}_{t-k}^{G E}, S P^{U S}$ & & neg & neg & neg & neg & neg & neg & neg & - \\
\hline auto.int $(8) ; \boldsymbol{x}_{t-k}^{G E}, S P^{G E}$ & & neg & neg & neg & neg & neg & neg & neg & - \\
\hline $\operatorname{static}(4) ; \boldsymbol{v}_{t-k}^{G E}$ & & 0.02 & 0.02 & 0.02 & 0.02 & 0.02 & 0.02 & 0.16 & 0.03 \\
\hline dyn.iter $(5), \boldsymbol{v}_{t-k}^{G E}$ & & 0.44 & 0.41 & 0.38 & 0.36 & 0.34 & 0.32 & 0.30 & - \\
\hline $\operatorname{auto}(7) ; \boldsymbol{v}_{t-k}^{G E}$ & & 0.20 & 0.20 & 0.19 & 0.19 & 0.19 & 0.19 & 0.19 & 0.27 \\
\hline auto.int $(8) ; \boldsymbol{v}_{t-k}^{G E}, S P^{G E}$ & & neg & neg & neg & neg & neg. & neg & 0.11 & - \\
\hline $\operatorname{static}(4) ; \boldsymbol{x}_{t-k}^{G E *}$ & & 0.41 & 0.40 & 0.38 & 0.38 & 0.38 & 0.38 & 0.35 & 0.28 \\
\hline dyn.iter (5), $\boldsymbol{x}_{t-k}^{G E *}$ & & 0.61 & 0.60 & 0.58 & 0.60 & 0.60 & 0.59 & 0.41 & - \\
\hline $\operatorname{auto}(7) ; \boldsymbol{x}_{t-k}^{G E *}$ & & 0.70 & 0.70 & 0.69 & 0.57 & 0.58 & 0.59 & 0.57 & 0.27 \\
\hline auto.int (8); $\boldsymbol{x}_{t-k}^{G E *}, S P^{G E}$ & & neg. & neg. & neg. & 0.49 & 0.51 & 0.52 & 0.57 & - \\
\hline
\end{tabular}

Notes: "Neg" means negative $p s R^{2}$-value. See also notes to Table 5. 
Table 8: Out-of-sample forecasting points of employed models in Germany.

\begin{tabular}{|c|c|c|c|c|c|c|c|c|c|}
\hline & $h$ & 10 & 11 & 12 & 13 & 14 & 15 & 16 & 21 \\
\hline model & $h^{f}$ & 1 & 2 & 3 & 4 & 5 & 6 & 7 & 12 \\
\hline $\operatorname{static}(4) ; \boldsymbol{x}_{t-k}^{G E}$ & & 0.53 & 0.49 & 0.49 & 0.50 & 0.48 & 0.50 & 0.48 & 0.50 \\
\hline dyn.iter $(5), \boldsymbol{x}_{t-k}^{G E}$ & & 0.66 & 0.64 & 0.63 & 0.61 & 0.60 & 0.60 & 0.55 & - \\
\hline $\operatorname{auto}(7) ; \boldsymbol{x}_{t-k}^{G E}$ & & 0.74 & 0.74 & 0.74 & 0.73 & 0.73 & 0.70 & 0.71 & 0.52 \\
\hline auto.int (8); $\boldsymbol{x}_{t-k}^{G E}, S P^{U S}$ & & 0.65 & 0.63 & 0.60 & 0.60 & 0.60 & 0.60 & 0.49 & - \\
\hline auto.int $(8) ; \boldsymbol{x}_{t-k}^{G E}, S P^{G E}$ & & 0.60 & 0.52 & 0.52 & 0.50 & 0.50 & 0.48 & 0.45 & - \\
\hline $\operatorname{static}(4) ; \boldsymbol{v}_{t-k}^{G E}$ & & 0.29 & 0.29 & 0.29 & 0.30 & 0.29 & 0.30 & 0.41 & 0.30 \\
\hline dyn.iter $(5), \boldsymbol{v}_{t-k}^{G E}$ & & 0.56 & 0.55 & 0.52 & 0.48 & 0.49 & 0.48 & 0.43 & - \\
\hline $\operatorname{auto}(7) ; \boldsymbol{v}_{t-k}^{G E}$ & & 0.44 & 0.44 & 0.44 & 0.44 & 0.42 & 0.42 & 0.41 & 0.42 \\
\hline auto.int (8); $\boldsymbol{v}_{t-k}^{G E}, S P^{G E}$ & & 0.52 & 0.52 & 0.52 & 0.52 & 0.52 & 0.52 & 0.50 & - \\
\hline $\operatorname{static}(4) ; \boldsymbol{x}_{t-k}^{G E *}$ & & 0.60 & 0.58 & 0.58 & 0.58 & 0.58 & 0.58 & 0.58 & 0.53 \\
\hline dyn.iter $(5), \boldsymbol{x}_{t-k}^{G E *}$ & & 0.72 & 0.71 & 0.67 & 0.69 & 0.67 & 0.67 & 0.61 & - \\
\hline $\operatorname{auto}(7) ; \boldsymbol{x}_{t-k}^{G E *}$ & & 0.81 & 0.81 & 0.81 & 0.71 & 0.71 & 0.71 & 0.70 & 0.53 \\
\hline auto.int $(8) ; \boldsymbol{x}_{t-k}^{G E *}, S P^{G E}$ & & 0.66 & 0.67 & 0.62 & 0.75 & 0.75 & 0.75 & 0.70 & - \\
\hline
\end{tabular}

Notes: See notes to Table 6. 
Table 9: The latest recession forecasts.

\begin{tabular}{|c|c|c|c|c|c|c|c|c|}
\hline month & $\begin{array}{c}U S \\
\text { static } \\
\boldsymbol{v}_{t-k}^{U S} \\
\end{array}$ & $\begin{array}{c}\text { dyn.iter } \\
\boldsymbol{x}_{t-k}^{U S} \\
\end{array}$ & $\begin{array}{l}\text { auto } \\
\boldsymbol{x}_{t-k}^{U S}\end{array}$ & $\begin{array}{c}\text { auto.int } \\
\boldsymbol{x}_{t-k}^{U S}, S P^{U S}\end{array}$ & $\begin{array}{c}G E \\
\text { static } \\
\boldsymbol{v}_{t-k}^{G E} \\
\end{array}$ & $\begin{array}{c}\text { dyn.iter } \\
\boldsymbol{x}_{t-k}^{G E *} \\
\end{array}$ & $\begin{array}{l}\text { auto } \\
\boldsymbol{x}_{t-k}^{G E *}\end{array}$ & $\begin{array}{c}\text { auto.int } \\
\boldsymbol{x}_{t-k}^{G E *}, S P^{G E}\end{array}$ \\
\hline 07M04 & 0.39 & 0.18 & 0.12 & 0.22 & 0.15 & 0.14 & 0.10 & 0.16 \\
\hline 07M05 & 0.43 & 0.22 & 0.14 & 0.27 & 0.17 & 0.16 & 0.09 & 0.17 \\
\hline 07M06 & 0.41 & 0.25 & 0.16 & 0.34 & 0.15 & 0.16 & 0.06 & 0.12 \\
\hline 07M07 & 0.40 & 0.26 & 0.18 & 0.39 & 0.14 & 0.16 & 0.04 & 0.07 \\
\hline 07M08 & 0.42 & 0.30 & 0.30 & 0.54 & 0.16 & 0.19 & 0.09 & 0.18 \\
\hline 07M09 & 0.43 & 0.33 & 0.33 & 0.62 & 0.16 & 0.19 & 0.05 & 0.13 \\
\hline 07M10 & 0.38 & 0.33 & 0.25 & 0.57 & 0.15 & 0.19 & 0.03 & 0.07 \\
\hline 07M11 & 0.33 & 0.32 & 0.20 & 0.52 & 0.14 & 0.20 & 0.04 & 0.10 \\
\hline 07M12 & 0.23 & 0.30 & 0.24 & 0.53 & 0.13 & 0.20 & 0.04 & 0.09 \\
\hline 08M01 & 0.29 & 0.31 & 0.33 & 0.61 & 0.16 & 0.23 & 0.10 & 0.19 \\
\hline 08M02 & 0.23 & 0.30 & 0.29 & 0.56 & 0.21 & 0.25 & 0.12 & 0.27 \\
\hline 08M03 & 0.20 & 0.29 & 0.21 & 0.45 & 0.22 & 0.30 & 0.16 & 0.41 \\
\hline 08M04 & 0.20 & 0.29 & 0.20 & 0.41 & 0.23 & 0.37 & 0.37 & 0.79 \\
\hline 08M05 & 0.15 & 0.29 & 0.33 & 0.49 & 0.24 & 0.44 & 0.59 & 0.94 \\
\hline 08M06 & 0.12 & 0.26 & 0.31 & 0.43 & 0.23 & 0.47 & 0.54 & 0.95 \\
\hline c.exp & 0.00 & 0.51 & 0.02 & 0.01 & 0.00 & 0.47 & 0.05 & 0.03 \\
\hline
\end{tabular}

Notes: "Real time" recession forecasts for the United States (left) and Germany (right). 

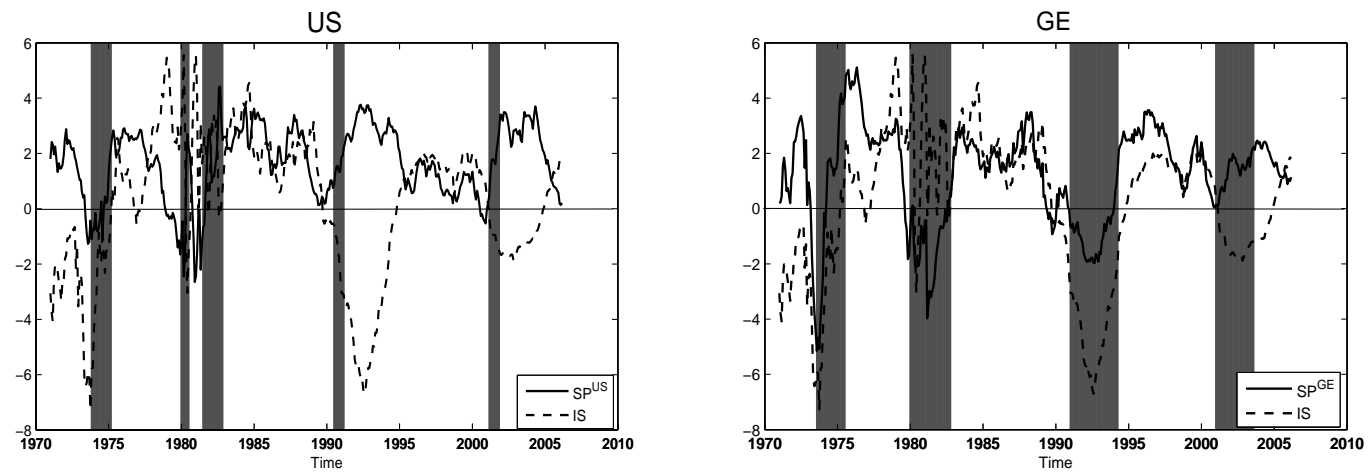

Figure 1: Recession periods with domestic term spread $S P_{t}$ and the interest rate differential $I S_{t}$. The United States $\left(S P_{t}^{U S}\right)$ is shown in the left panel, Germany $\left(S P_{t}^{G E}\right)$ in the right panel.
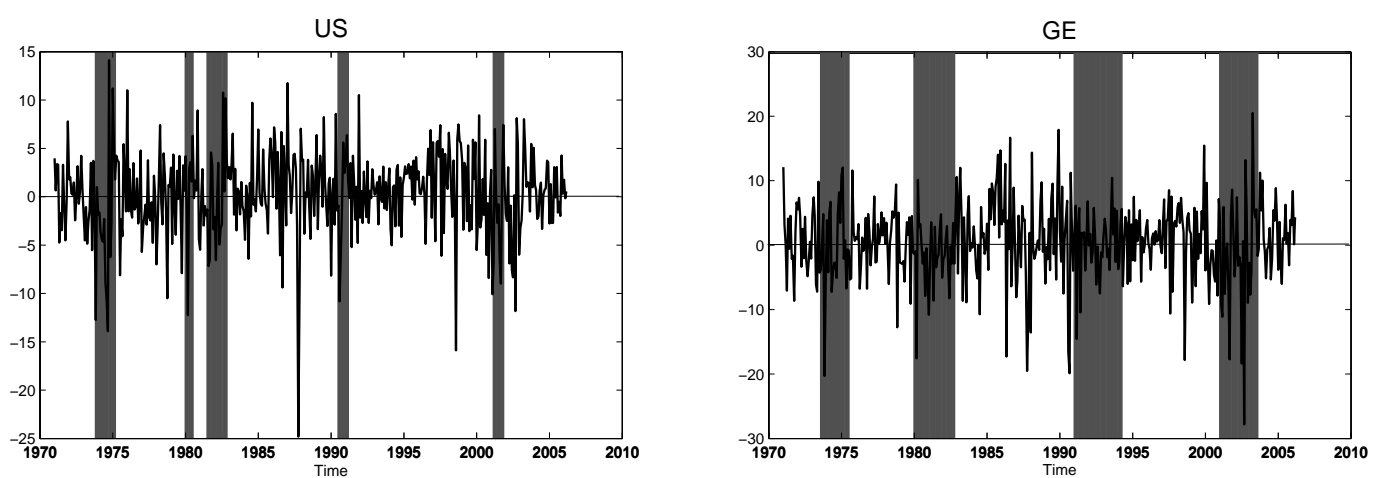

Figure 2: Recession periods with stock returns $r_{t}$. The United States $\left(r_{t}^{U S}\right)$ is shown in the left panel, Germany $\left(r_{t}^{G E}\right)$ in the right panel. 

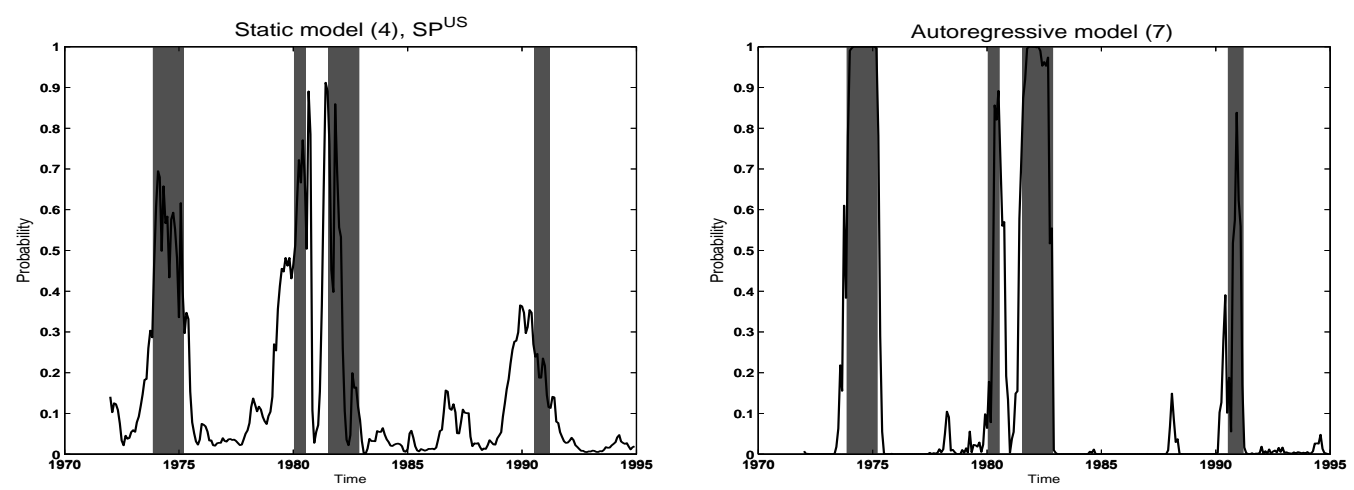

Figure 3: The static and autoregressive in-sample predictive models for the United States.
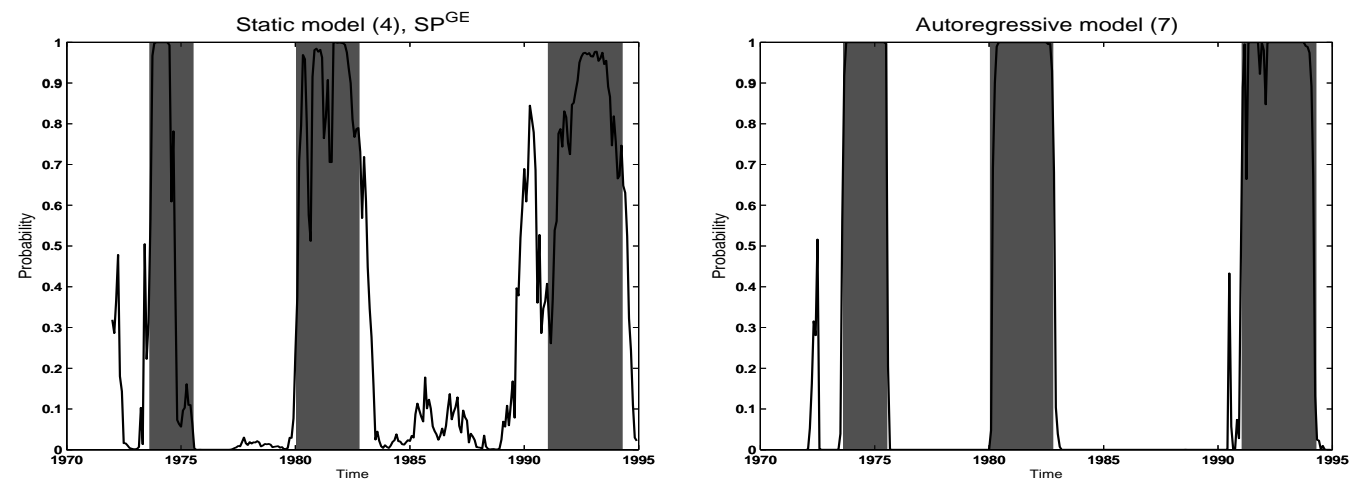

Figure 4: The static and autoregressive in-sample predictive models for Germany. 

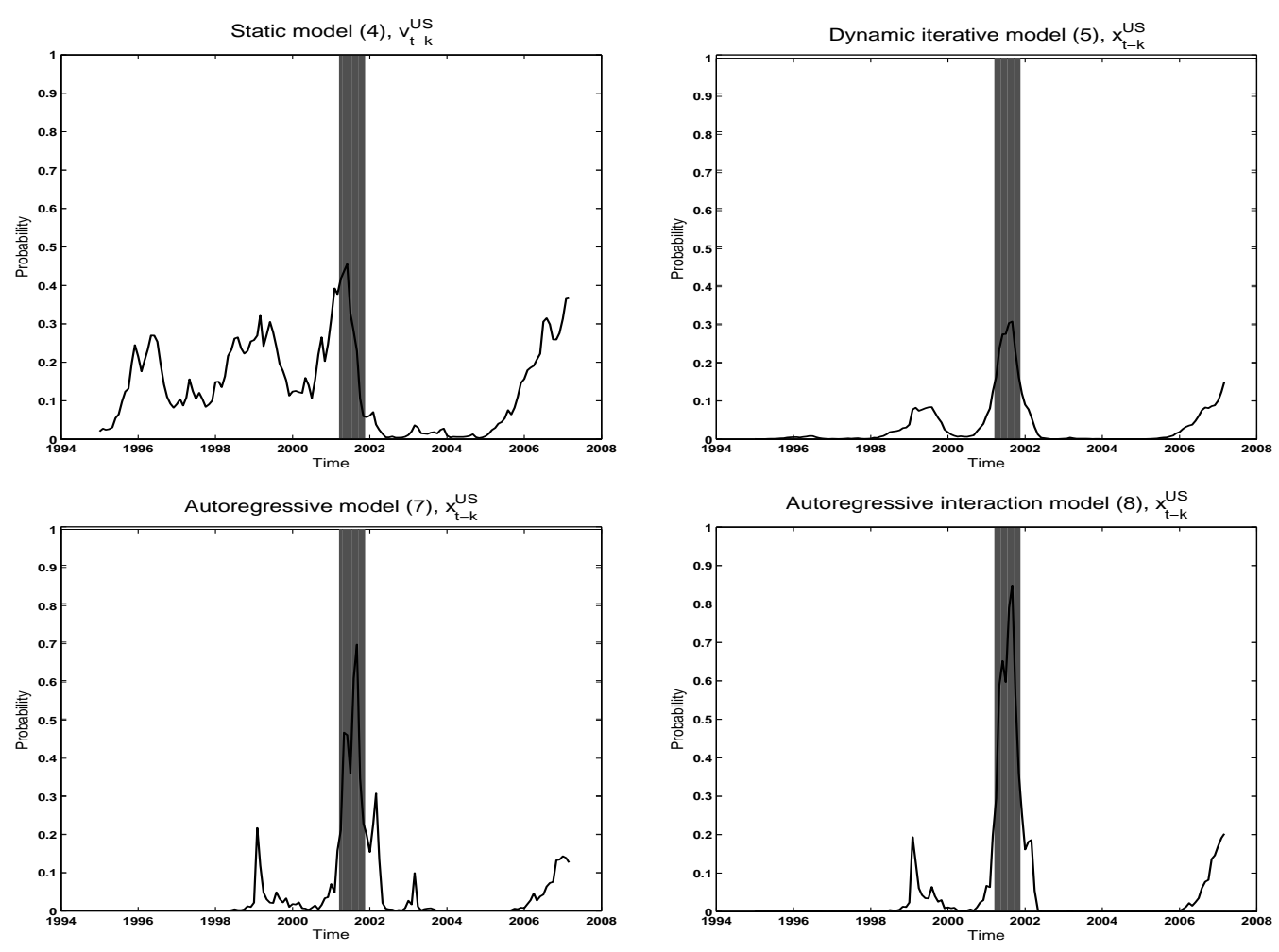

Figure 5: The best out-of-sample forecasting models for the United States.
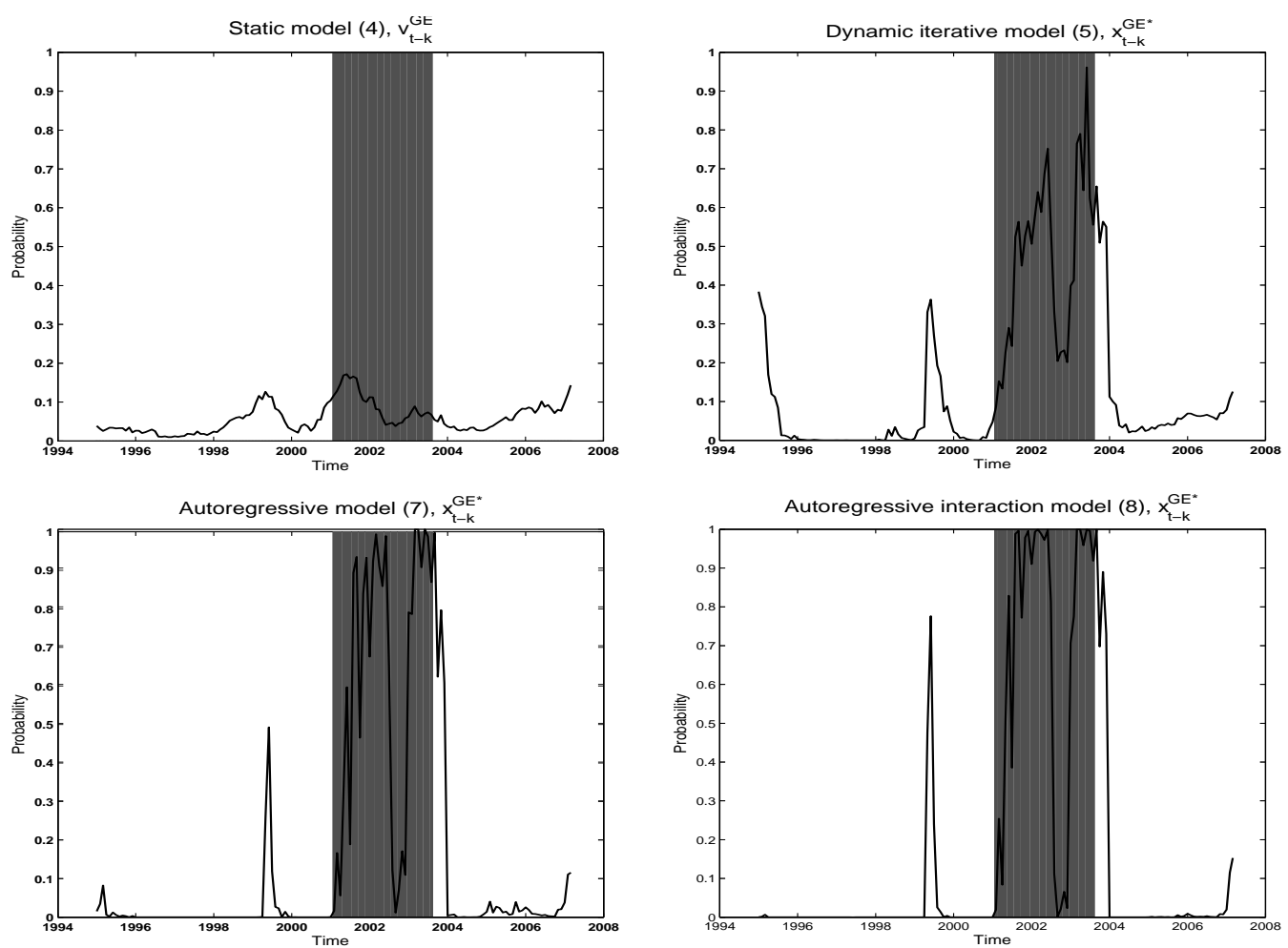

Figure 6: The best out-of-sample forecasting models for Germany. 